
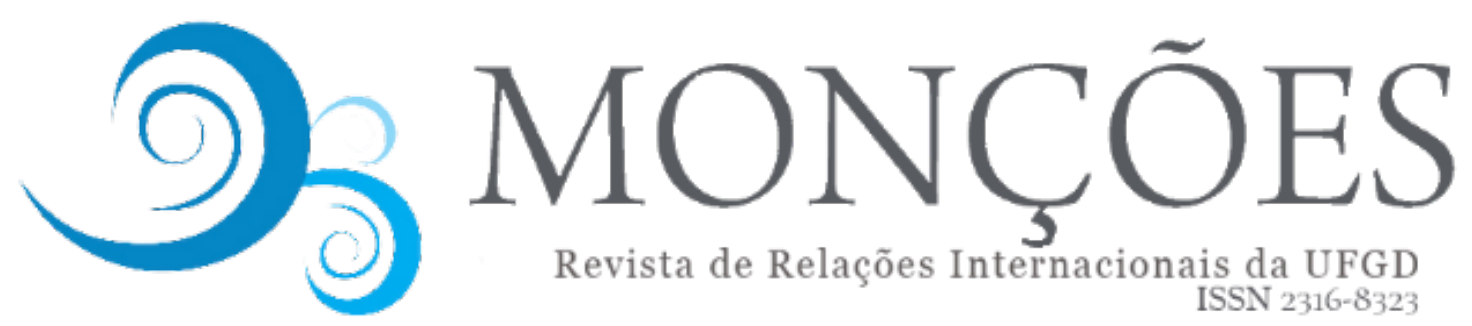

Revista de Relações Internacionais da UFGD

ISSN $2316-8323$

\title{
O PALÁCIO É A CASA: DISTINÇÃO E BUROCRACIA
}

\author{
KARLA GOBO \\ Professora Doutora da Escola Superior de Propaganda e Marketing \\ e da Universidade Veiga de Almeida
}

\begin{abstract}
RESUMO: Longe de ser um aspecto arbitrário, ou produto da incorporação de elementos, técnicas, tendências e escolas incorporadas por profissionais de arquitetura, paisagismo e decoração, a edificação de casas, prédios ou instituições públicas buscam também evidenciar o habitus de seus agentes. Tendo em vista esta premissa, o objetivo deste trabalho é apresentar a relação entre o habitus diplomático e as sedes do Ministério das Relações Exteriores. Para tanto buscou-se compreender primeiro o que é e como se organiza essas disposições e como elas estão expressas nas duas edificações da diplomacia brasileira.
\end{abstract}

PALAVRAS-CHAVES: Arquitetura; Palácio do Itamaraty; Burocracia.

\section{THE PALACE IS HOME: DISTINCTION AND BUREAUCRACY}

ABSTRACT: Far from being an arbitrary aspect or product of the incorporation of elements, techniques, trends and schools incorporated by professionals of architecture, landscaping and decoration, the construction of public houses, buildings or institutions also seek to highlight the habitus of its agents. In view of this premise, the objective of this work is to present the relationship between the diplomatic habitus and the headquarters of the Ministry of Foreign Affairs. In order to do so, we sought to understand first what is and how these provisions are organized and how they are expressed in the two buildings of Brazilian diplomacy.

KEYWORDS: Architecture; Itamaraty Palace; Bureaucracy.

\section{Introdução}

No último ano se comemorou meio século da primeira recepção oficial a autoridades estrangeiras na nova sede da diplomacia brasileira em Brasília. Observando a Esplanada do Ministério, vê-se ao fundo o Congresso Nacional, e ao seu lado duas edificações que diferem dos blocos arquitetônicos idênticos projetados por Oscar Niemeyer e Lúcio Costa para abrigar os ministérios na capital do país. O primeiro, o Palácio da Justiça, dada a nossa tradição bacharelesca e o espaço que o judiciário ocupa tanto no plano histórico, simbólico e econômico do país, não é difícil imaginar que seu espaço teria destaque especial. Entretanto, qual 
seria a explicação para uma edificação moderna, mas com elementos que remetem à tradição e história do país, repletas de obras de arte e mobiliário de diferentes momentos e escolas que se têm no Ministério das Relações Exteriores? Lembrando que não se trata de um espaço politicamente disputado pelos partidos e que não recebe grande fatia do orçamento ${ }^{1}$. Praticamente metade da receita do ministério é destinada para pagamento de pessoal ${ }^{2}$. Com uma fatia tão pequena do orçamento, sem apelo político-eleitoral, então por que uma arquitetura tão distinta dos demais?

Para compreender e explicar essas perguntas, é preciso se debruçar não apenas sobre os aspectos históricos e simbólicos que cercam as edificações do Rio de Janeiro e de Brasília. Mas, considerando a correspondência entre arquitetura e àquele que ocupa este espaço, é também preciso compreender quais são as disposições e os capitais do grupo que desfruta dessas edificações, símbolo da arquitetura brasileira.

Em outras palavras, o Itamaraty não é apenas mais um ambiente de trabalho de uma burocracia. Ele carrega uma série de signos que são a própria representação materializada de seus agentes. Há vários elementos para análise, o primeiro deles é a denominação "palácio" que em si leva a duas interpretações possíveis. A primeira é dada à residência dos monarcas e chefes de Estado. A outra é o caráter suntuoso e distintivo que esta denominação carrega. Se não lhe cabe uma grande fatia do orçamento, o poder simbólico dessa burocracia está objetificado no seu habitus ${ }^{3}$ e materializado no espaço, podendo ser compreendido a partir da gênese desse campo.

Ao longo da história, o corpo diplomático brasileiro se constituiu como distinto do restante da burocracia de Estado. Desde seus primórdios, no século XIX, tratouse de um campo em que critérios de distinção - que consideravam fluência em línguas estrangeiras, conhecimentos estabelecidos de arte e cultura, naturalidade no

\footnotetext{
${ }^{1}$ É o caso do Ministério dos Transportes, Cidades e Integração Nacional, que controlam grande parte dos investimentos, sobretudo em obras públicas. Dentre os 23 ministérios, o Itamaraty ocupa a posição $20^{\circ}$ receita destinada a esses espaços.

${ }^{2}$ De acordo com os dados do Ministério do Planejamento (2018), R\$1.023.747.454 da receita de R\$ 2.206.637.116 foram gastas com pessoal e encargos sociais.

3 "Os condicionamentos associados a uma classe particular de condições de existência produzem habitus, sistemas de disposições duráveis e transponíveis, estruturas estruturadas predispostas a funcionar como estruturas estruturantes, ou seja, como princípios geradores e organizadores de práticas e de representações que podem ser objetivamente adaptadas ao seu objetivo sem supor a intenção consciente de fins e o domínio expresso das operações necessárias para alcançá-los, objetivamente 'reguladas' e 'regulares' sem em nada ser o produto da obediência a algumas regras e, sendo tudo isso, coletivamente orquestradas sem ser o produto da ação organizadora de um maestro." (BOURDIEU, 2009, p. 87)
} 
uso das etiquetas e nas formas de se vestir - foram postos como elementos fundamentais para o exercício da profissão. $O$ trecho a seguir expressa muito bem esses imperativos culturais:

Não eram os diplomatas brasileiros parecidos entre si, como éramos também parecidos com todos os diplomatas do mundo - mas um mundo que consistia em uns quarenta países, dentre os quais talvez uma dúzia ou pouco mais que de fato contassem. Integrávamos uma elite, uma comunidade global que compartilhava estilos e práticas. Essa crème de la crème internacional se entendia em francês, a língua diplomática par excellence. Compreende-se esse tribalismo elitista. Era prático que agissem todos sob um mesmo código e que, literal e metaforicamente, falassem a mesma língua [...] O Itamaraty era então - e sobretudo - a Casa da elite. Diria mais: era o lugar que reunia a elite da elite, e sua legitimação derivava de se perceber e de ser percebida como núcleo de qualidade e excelência. Com a criação do Instituto Rio Branco, deixou de ser uma Casa de elite por seleção aristocrática para ser também uma Casa de elite por seleção intelectual. O conceito de elite não só permaneceu como robusteceu... (AZAMBUJA. 2011, s/p)

Ao passo que a diplomacia brasileira era muito diferente dos seus representados, era também muito semelhante às demais existentes pelo mundo, constituindo uma unidade global que compartilhava estilos e práticas, como ressalta Azambuja (2011). Em outras palavras, independente das diferenças culturais ou de nacionalidade, cultivam-se traços distintivos capazes de unir os diplomatas do mundo, ou do mundo que importa: aqueles que dentre outras coisas, têm em comum o culto e a valorização dos signos mais consagrados nas sociedades ocidentais, sobretudo de origem europeia com acento francês. Essa cultura não é uma cultura nacional, mas uma cultura legítima internacional, atuante em qualquer país com uma elite que cultiva la politesse. La politesse é o que une essa elite da elite anteriormente citada, é a capacidade de seguir as regras de sofisticação, de etiqueta, de bom gosto francês.

A distinção no mundo social unifica e distancia. Através dela é possível estabelecer os capitais simbólicos que serão avaliados e disputados em cada campo (BOURDIEU, 1979). Sendo uma forma de poder simbólico, ela empodera e dá coesão aos agentes que dominam essas disposições naturalizadas. Assim como exerce a violência simbólica para os de fora ou para aqueles que não dominam esses signos com naturalidade. Neste sentido, 
...a aparência física da casa no espaço é um símbolo da posição, da importância, do nível de sua 'casa' no tempo, ou seja, de sua estirpe no decorrer das gerações, com isso simbolizando também a posição e a importância que ele mesmo possui como representante vivo da casa. (ELIAS. 2001, p. 75)

A relação campo-habitus está simbolizada, em grande medida, na relação Palácio do Itamaraty-diplomatas brasileiros. Trata-se do campo pensado como espaço de estilização da vida diplomática e de seu mais reconhecido representante. É a casa da diplomacia brasileira, local em que a representação do Estado brasileiro se faz presente para os da casa e para os de fora. É a Casa de Rio Branco, seu patrono, que dada as condições do início do século, consegue estabelecer determinado modus operandi que é reproduzido ao longo do tempo.

Para a pesquisa julgou-se necessário buscar as informações, publicações e agentes institucionalizados, isso quer dizer, além de estudos publicados pela Fundação Alexandre de Gusmão, também foram utilizadas memórias, entrevistas e biografias de vários desses diplomatas brasileiros. Foi também apresentado alguns dados do survey realizado com este grupo em 2015 com 208 respostas e as observações do grupo realizada durante os anos de pesquisa.

Para melhor compreensão da especificidade deste espaço, o presente texto é composto de duas seções. A primeira busca expor a história da instituição e algumas peculiaridades de seu habitus. E a segunda como esses esquemas simbólicos se materializam na arquitetura e decoração desse espaço de estilização diplomática.

\section{O espaço e habitus diplomático.}

As regras institucionais são a forma mais objetiva de modelar o comportamento dos agentes. Como já foi dito na introdução, o Ministério das Relações Exteriores surge sob o nome de Negócios Estrangeiros e é uma das primeiras burocracias brasileiras, juntamente com o Exército, fundados logo após a Independência (1822) (LOUREIRO, ABRUCIO E PACHECO, 2010). 
Até 1931 havia duas áreas distintas no Itamaraty: a consular e a diplomática (FARIA. 2008), cada qual com métodos de recrutamento diferentes, principalmente no que diz respeito à origem social e utilização do concurso público. A carreira consular era aquela capaz de gerar emolumentos. Como fica evidente na biografia do Barão do Rio Branco (VIANNA, 2008), ser Cônsul em Liverpool era um dos melhores postos para gerar os rendimentos necessários para sustentar a família. Na carreira diplomática, para o desempenho de papéis de representação do Brasil no exterior, era preciso ter fortuna pessoal. Em diversos casos eram as fortunas pessoais que financiavam as festas e bailes nas embaixadas, um caso bastante conhecido foi o de Barão de Penedo. Em resumo, fortuna e capital simbólico ${ }^{4}$ - cultural ou social - eram aspectos importantes para se tornar diplomata. As funções de representação exigiam desses funcionários de Estado riqueza e aspectos legitimados e naturalizados de sofisticação para representar o Brasil, por isso o Embaixador Marcos Azambuja trata este grupo como sendo a elite da elite do país: aquela que dispunha de capital econômico e cultural, com disposição de colocá-los à serviço da representação do Brasil no exterior.

Além do capital econômico e cultural, o capital social também era um elemento importante para a inserção na carreira. Sua materialização se dava através das relações com as elites política e diplomática: "O usual, como ocorria na diplomacia europeia, eram políticos e diplomatas inserirem seus próprios filhos na carreira" (FARIA. 2008). O interesse na carreira advinha também do prestígio que ela ocupava. Durante os anos do II Reinado (1840-1889) o Itamaraty era considerado a pasta mais importante (SCHUWARCZ, 2012).

A racionalidade burocrática vai tomando espaço a partir de 1920, culminando na criação do Instituto Rio Branco em 1945 (FARIAS E CARMO, 2015). A partir desse momento, assiste-se a uma queda do capital social e a valorização do capital cultural na forma de recrutamento, que passaram atender regras claras e explícitas. Entretanto, dizer que o processo tenha se tornado meritocrático não implica que o acesso ao campo diplomático se tornou universal, já que mulheres, negros, minorias sexuais, homens brancos de baixa estatura, mais velhos ou com deficiência foram, de diferentes maneiras, excluídos desse espaço. A mudança no

\footnotetext{
4 "O capital simbólico é uma propriedade qualquer (de qualquer tipo de capital; físico, econômico, cultural, social), percebida pelos agentes sociais cujas categorias de percepção são tais que eles podem entende-las (percebê-las) e reconhece-las, atribuindo-lhes valor)" (BOURDIEU, 2005, p. 107).
} 
recrutamento não levou necessariamente à mudança no perfil dos atores recrutados, pois a avaliação visava selecionar justamente agentes muito semelhantes aos que já estavam lá (CHEIBUB, 1984, 1985).

Quanto ao habitus, o domínio das regras de etiqueta, por exemplo, são parte importante do habitus diplomático e constitutivas de seu campo. Trata-se de um tema bastante presente nas memórias desses agentes. No relato do ministro dos anos Figueiredo (1979-1985) as recepções têm lugar de destaque.

Quando Claude Cheysson veio a Brasília, orientei o cerimonial para eu, no almoço que lhe seria oferecido, não servíssemos comida francesa. Uma pobre contração seria muito pior do que algum prato exótico, mas autêntico. Foi servido arroz de tropeiro, que o visitante repetiu com gosto. Ficou particularmente entusiasmado por um vegetal e me perguntou do que se tratava. Expliquei-Ihe que era um chou, dito couve mineira, muito apreciado no Brasil, que existia na Europa onde era empregado somente como forragem para animais. Era da família das chicórias. Cheysson observou, então, que era melhor do que a chicória, vegetal muito azedo, ao passo que aquela couve tinha a medida exata de amargor para ter personalidade, sendo agradável. Não poderia concordar mais com o homenageado. Em minha opinião, trata-se de produto refinado. (GUERREIRO. 1992, p. 120)

Já nas afirmações do Embaixador Marcos Azambuja ${ }^{5}$, nota-se claramente que o saber receber, oferecer um almoço ou jantar oficial ${ }^{6}$, entender de vinho, colocar as pessoas corretamente sentadas, em suma, entender da arte do cerimonial, é entendido como algo que também é levado em consideração nas negociações e nas relações.

A caricatura ganhava contornos mais nítidos quando se pensava no cerimonial e nas regras do protocolo. Como venho da Casa, tenho robusto respeito por essas atividades tão próximas do âmago do saber diplomático. Postas de lado as mesuras e as afetações extravagantes, cerimonial é, na essência, duas coisas de difícil execução: a administração e a conciliação das vaidades pessoais e nacionais; e a montagem de operações diplomáticas como viagens, congressos, conferências e solenidades de todo tipo. Dá mais trabalho do que

\footnotetext{
${ }^{5}$ Ex-embaixador na França e na Argentina e ex-secretário geral do Itamaraty no governo Collor de Mello (1990-1992).

${ }^{6}$ Christian Lequesne, ao analisar o caso francês do Quai d'Orsay, disserta sobre a importância das refeições neste espaço como parte obrigatória da prática profissional. Disponível em: http://www.lemonde.fr/idees/article/2016/08/28/les-ambassadeurs-vivent-les-repas-comme-unepratique-professionnelle-obligatoire_4988899_3232.html.
} 
parece, e os riscos de um vexame à vista de todos são inúmeros. $\mathrm{O}$ erro é risco universal (AZAMBUJA. 2011).

O cerimonial e as regras do protocolo não são atividades paralelas ou acessórias. Por meio delas são confirmados o prestígio e a posição de poder de seus agentes perante os demais. Este jogo relacional presente nas aristocracias permanece aqui de forma bastante vívida. A honra e a glória de um indivíduo, estendidas aqui aos Estados, são questões que se solucionam no interior do próprio jogo institucional, ou seja, para alcançar e manter esses princípios é preciso se submeter política e simbolicamente ao soberano, como se assiste nas sociedades de corte especialmente após Luís XVI (ELIAS, 2001). A materialização desses aspectos simbólicos se dá principalmente por meio do exercício do cerimonial daquele que recebe. A ordem de precedência, por exemplo, tem de lidar com variáveis como a antiguidade dos agentes nos postos diplomáticos e a importância naquela relação entre aquele indivíduo/Estado que está recebendo e indivíduo/Estado convidado. Dessa forma, um erro na hora de estabelecer os lugares para um jantar oficial, neste contexto, fere a honra não só do indivíduo, mas sobretudo de seu Estado (TOMASS. 2001).

Quanto ao comportamento individual desses agentes, nota-se, sobretudo naqueles que estão há mais tempo neste espaço, o valor atribuído há alguns aspectos particulares. Na decoração da casa, por exemplo, há aspectos bastante peculiares, como elementos que remetem a várias partes do mundo: objetos de decoração, louças, tapetes, ou seja, aspectos materializados do capital simbólico que esses agentes carregam. Obras de arte de artistas renomados (Di Cavalcanti, Djanira, Tomie Otake, dentre outros), assim como móveis e retratos a óleo de parente ilustres, geralmente da nobreza brasileira, também fazem parte do mobiliário de alguns. Essa observação, feita sobretudo nas residências de diplomatas aposentados não é uma peculiaridade deste grupo, no survey, com 208 diplomatas ativos, percebe-se a importância que eles dão para eles elementos de representação de cultura e bom gosto.

TABELA 1 - Consumo de arte

\begin{tabular}{|c|ccc|}
\hline \multicolumn{4}{|c|}{ Compra ou já comprou obras de arte } \\
\hline Educação & Sim & Não & N \\
\hline Capitais dos Estados & $64,5 \%$ & $35,5 \%$ & 107 \\
\hline
\end{tabular}




\begin{tabular}{|l|llc|}
\hline Demais Capitais & $65,6 \%$ & $34,4 \%$ & 61 \\
Interior & $58,8 \%$ & $41,5 \%$ & 41 \\
\hline TOTAL & $63,6 \%$ & $36,4 \%$ & 209 \\
\hline
\end{tabular}

Fonte: Survey. Elaboração da autora

Esses aspectos apresentam elementos para a circunscrição de um habitus diplomático, que pode ser definido como um conjunto de disposições associado a um capital simbólico específico ao grupo ${ }^{7}$, que é objetivado nas vestimentas, no domínio das regras de etiqueta e de vários idiomas, nos gostos por arte, literatura, política e, sobretudo, na capacidade de opinar e falar sobre diversos assuntos.

\section{O Palácio, a casa ou "O Palácio é a casa"?}

Este ambiente é dedicado à representação social do Estado brasileiro, local onde se recebe as delegações estrangeiras e se realiza inclusive a cerimônia de posse do Presidente da República. Neste espaço seus agentes incorporam, expõem e dão sentido aos seus princípios de visão e divisão do mundo.

FIGURA 1 - Esplanada dos Ministérios

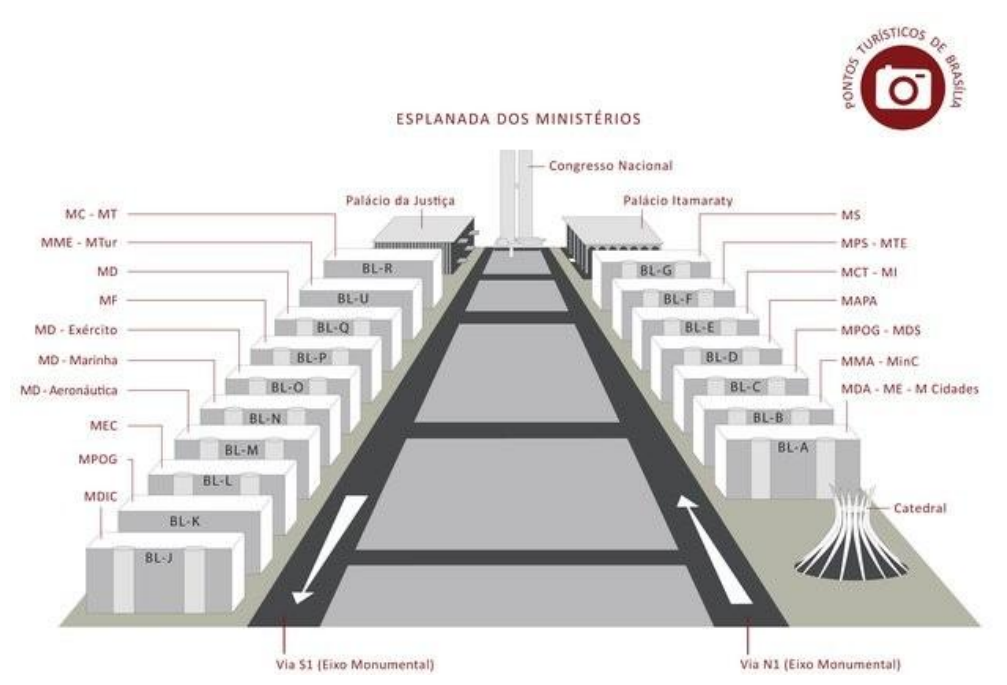

Fonte: http://www.designup.pro.brl. (2015)

7 "O capital simbólico é uma propriedade qualquer (de qualquer tipo de capital; físico, econômico, cultural, social), percebida pelos agentes sociais cujas categorias de percepção são tais que eles podem entendê-las (percebê-las) e reconhecê-las, atribuindo-lhes valor)" (BOURDIEU, 2005, p. 107). 
Como se pode ver, ademais do Ministério das Relações Exteriores e o Ministério da Justiça, somente o Congresso Nacional tem uma arquitetura própria. $\mathrm{E}$ somente esses dois espaços carregam a denominação de Palácio. É importante salientar que no site do governo federal, ao contrário do que a imagem mostra, os dois Palácios e a catedral não constam como parte do complexo arquitetônico denominado Esplanada dos Ministérios ${ }^{8}$, embora sejam igualmente órgãos do executivo federal.

A diferença entre as edificações reproduz a distinção deste espaço/agentes em relação aos demais ministérios/burocratas. Não se trata de riqueza ou do tamanho do orçamento. A arquitetura está inscrita no campo cultural, que lida com determinações reproduzidas e alimentadas por uma forma social e histórica de funcionamento (NASCIMENTO, 2017). Sendo assim, o ambiente ocupado reafirma o poder e a posição social histórica do ocupante e o dever de se diferenciar de seus pares. Os significados e sentidos que devem ser apreendidos não estão apenas nas regras e nos seus agentes, estão também materializados em seus lugares de representação.

Itamaraty. Casa. Duas palavras que significam muito para nós. A sede da diplomacia brasileira é o palácio que deu o nome pelo qual nosso serviço exterior é conhecido no Brasil e no mundo: Itamaraty. Mas a nossa Casa, nossa sede espiritual, leva o nome de Rio Branco. A Casa de Rio Branco. Usamos a imagem do Palácio Itamaraty quando tratamos de formalidades, eventos, posturas ou linhas que seguimos. Utilizamos a expressão "a Casa" para nos referirmos a uma determinada cultura que nos singulariza; um certo modo de fazer o que nos compete; um certo jeito plural de encarar o Brasil, o mundo, o Brasil no mundo e o mundo no Brasil (CORRÊA, 2012, s/p.)

Como fica evidente na fala do Embaixador ${ }^{9}$, a referência usada não é como Ministério, mas pela alcunha que este espaço ficou tradicionalmente conhecido. A

\footnotetext{
${ }^{8}$ No site a descrição é "A área da Esplanada é um vasto gramado com 17 prédios de construção uniforme, que abrigam os ministérios, que são os órgãos do Poder Executivo. Ao final da sua extensão, encontra-se 0 Congresso Nacional" (Disponível em: http://www.brasil.gov.br/governo/2010/03/esplanada-dos-ministerios)

${ }^{9}$ Luiz Felipe Seixas Corrêa foi Chefe de Missão no México, na Espanha, na Argentina, na Delegação do Brasil em Genebra (ONU e OMC), na Alemanha, na Santa Sé e no Consulado Geral em Nova York. No Brasil foi Assessor do Chefe do Gabinete Civil (1983/1985) e Conselheiro Internacional do Presidente da República (1987/1989). Alcançou o posto de Secretário Geral do Ministério das Relações Exteriores em duas ocasiões (1992 e 1999-2001).
} 
outra referência dada a esta instituição, que tem íntima relação com a construção da indissociabilidade entre o profissional e o privado na construção do espírito de corpo, é a utilização oficial do termo Casa, que é inculcado já nas aulas de linguagem diplomática do Instituto Rio Branco. O objetivo é que o termo seja usado nos documentos oficiais dirigidos a outros diplomatas brasileiros. Considera-se que o termo não se deve apenas a um regramento burocrático do Itamaraty, mas indica também a indissociação do espaço de figuração entre a vida privada e a profissional. Trata-se também de um jogo em que se define quem é e quem não é da casa. Para estes, a Casa não é mera formalidade ou sinônimo de reverência ao local de trabalho, pois a diplomacia não é vista como profissão, mas como uma vocação ${ }^{10}$, não devendo os indivíduos imbuídos dela dissociá-la de sua vida pessoal.

Digamos que exista um modelo $A$, que é mono direcionado, que vai se dedicar exclusivamente àquela profissão, que tem todo um sistema de backup, quer dizer, ele tem a casa dele arrumada, ele tem as coisas arrumadas. Ele tem quem cuide dele. $\mathrm{E}$ tem o modelo $\mathrm{B}$, que quer trabalhar, quer vir aqui trabalhar de $9 \mathrm{~h}$ às $19 \mathrm{~h}$, executar tarefas e tem toda uma vida fora, com outros interesses. Acho que historicamente e socialmente os homens acabam se conformando no modelo $A$, e as mulheres acabam caindo no modelo B. Agora existem diferenças individuais, conheço muitos homens que têm relacionamento 9-19h com o Itamaraty. São pessoas que sofrem extremamente, têm dificuldades de conseguir remoção, de serem reconhecidos, têm dificuldade de aceitar a lógica da casa, isso aqui é uma corporação, não é a Petrobrás, não é o Banco do Brasil. (BALBINO, 2011, p. 115)

Se para os estabelecidos aquele espaço é a casa, para os outsiders ele é o Palácio, o domicílio de Chefes de Estados, reis ou nobres. A construção de Brasília não teria o nome de Itamaraty, mas continuaria com a denominação de Palácio, desta vez Palácio dos Arcos. No entanto, pela tradição, aspecto mais cultivado entre as sociedades de corte do que nas burguesas (ELIAS, 2001), acabou se mantendo a denominação da antiga capital, Palácio do Itamaraty.

[...] o nome não vingou e renasceu no Planalto Central o nome Itamaraty que trazíamos do Rio e do velho casarão da rua Larga de

\footnotetext{
10 Vocação é entendida aqui como "mera transfiguração ideológica da relação que se estabelece objetivamente entre uma categoria de agentes e um estado de demanda objetiva, ou melhor, do mercado de trabalho, e que se concretiza através de uma carreira por intermédio do sistema de disposições produzidas pela interiorização de um tipo determinado de condições objetivas envolvendo um tipo determinado de oportunidades objetivas" (BOURDIEU, 2007, p. 200).
} 
São Joaquim como a sugerir que não se alteravam, com a mudança de endereço, o estilo, as tradições e mesmo os valores da nossa maneira de nos relacionarmos com o mundo. (AZAMBUJA, 2011, s/p.)

O nome do Palácio carrega a história do primeiro Barão de Itamaraty, Francisco José da Rocha Leão. De origem portuguesa, Francisco veio ao Brasil e se instalou no Rio de Janeiro, fazendo fortuna e

[...] dentro de alguns anos de ininterrupta atividade, enriqueceu no comércio do café e das pedras preciosas, tornando-se uma das primeiras figuras da sociedade carioca, vindo a falecer, cercado do respeito geral, a 6 de junho de 1853, em pleno apogeu da época imperial, firmado na paz interna obtida pela conciliação dos partidos e no prestígio exterior iluminado pela vitória de Caseros. (BARROSO, 1968, p.14)

No Rio de Janeiro, o futuro endereço da diplomacia foi antes sede da recémcriada República, sendo cedida ao Ministério das Relações Exteriores em 1899. Em 1902, Rio Branco assume o Ministério e retoma muitas das práticas da monarquia ${ }^{11}$, transformando este espaço em um dos mais concorridos para a estilização da vida da elite carioca no início da República. Em outras palavras, o Palácio do Itamaraty, no Rio de Janeiro, foi um ambiente de socialização e afirmação do processo civilizador brasileiro que se iniciou com a vinda da família real.

FIGURA 2 - Palácio do Itamaraty, Rio de Janeiro: vista externa

\footnotetext{
11 “...os teatros eram uma das grandes atividades da corte, as maiores diversões consistiam sem dúvida nos bailes e serões. Wanderley Pinho define de maneira precisa as artes que se esmeram em um salão: "a de receber ou preparar um ambiente de cordialidade e espírito; a de entreter uma palestra ou cultivar o humor; a de dançar uma valsa ou cantar uma ária, declamar ou inspirar versos, criticar com graça e sem maledicência, realçar a beleza feminina nas invenções da moda (...)" (Schuwarcz, 2012, p. 113)
} 


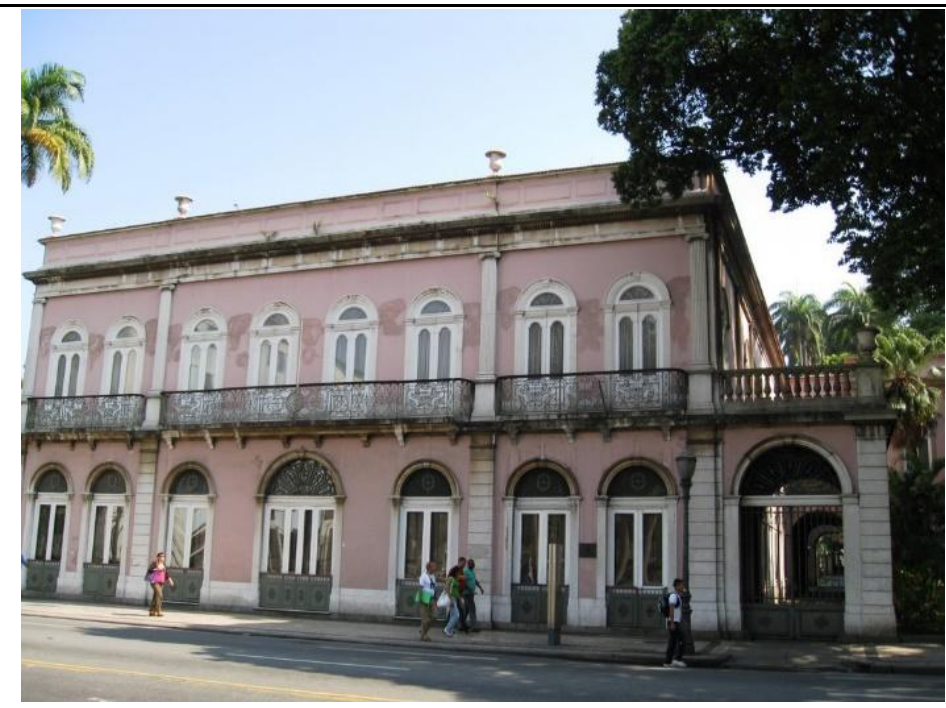

Fonte: www.panoramio.com. (2015)

FIGURA 3- Palácio do Itamaraty, Rio de Janeiro: vista interna

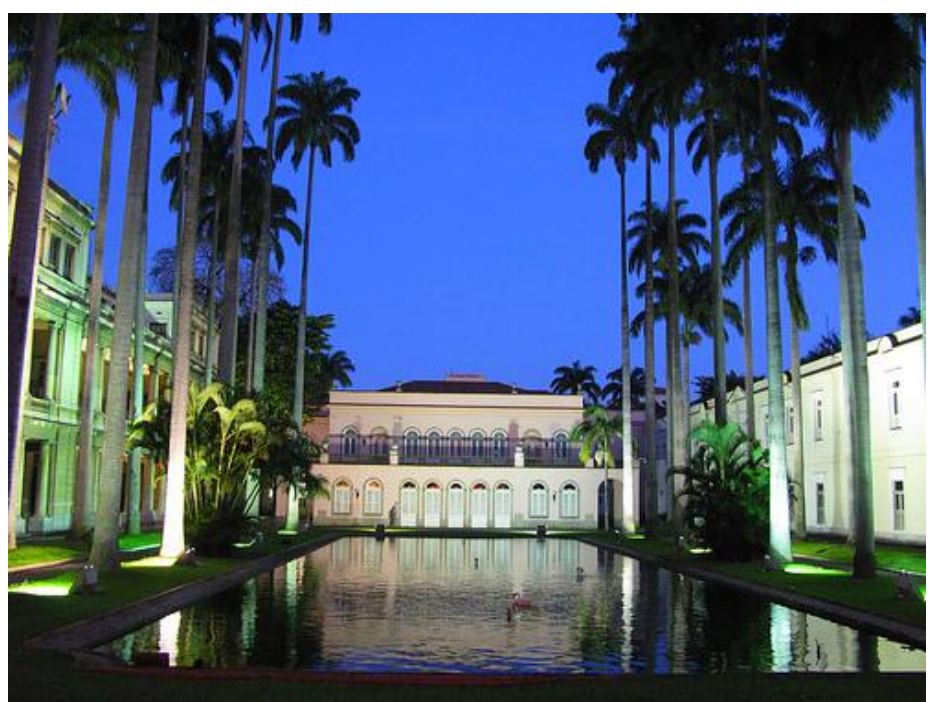

Fonte: www.flickr.com. (2015)

Este passou a ser um espaço de disputa da elite carioca ${ }^{12}$. A presença neste ambiente simbolizava status, riqueza, sofisticação, ou seja, distinção. O Palácio

12 "Em 1906, Rio Branco encomendou, para decorar as paredes da escadaria da entrada principal do Palácio do Itamaraty, a execução pelo pintor Rodolfo Amoedo de uma série de painéis com alegorias greco-romanas abstratas, mas que registram, de modo algo críptico, doze datas em algarismos romanos (CONDURU, 2010). Cada um desses anos está relacionado com eventos da história brasileira. Com alguma imaginação, quase como em uma metáfora religiosa, o visitante pode percorrer doze 'estações' da história brasileira (e não as quatorze da via-crúcis), em eventos emblemáticos que não terão sido escolhidos ao acaso: a chegada da esquadra de Cabral (1500); a instalação da primeira capital da colônia (1549); a restauração portuguesa (1640); a chegada de D. João VI (1808); elevação do Brasil a Reino Unido (1815); a nomeação do D. Pedro como regente (1821); a declaração da Independência (1822); a vitória contra Rosas (1852); o Tratado da Tríplice Aliança (1865); a vitória contra Solano Lopéz (1870); a Lei do Ventre Livre e a Lei Áurea (1871 e 1888) e a proclamação da República (1889)" (SANTOS, 2012, p. 161) 
torna-se um ambiente de sociabilidade num momento em que a remodelação da cidade ““ [...] a valorização do chique europeu (Art Nouveau), o frenesi com que se vive a agitação dos novos tempos, o advento da eletricidade nas casas e nas ruas, são transformações vividas sob o signo do moderno" (ORTIZ, 2006, p. 186). Esse signo do moderno estava necessariamente atrelado aos produtos e gostos europeus.

[...] nesse tempo, encomendava na Europa tudo o que lhe parecia indispensável no Itamarati [sic], desde o papel timbrado às alfaias do palácio, do cordão de cores [sic], para costurar tratados e outros papéis diplomáticos, e tratados sôbre [sic] Direito Internacional, enquanto projetava obras para dar à sede de seu ministério certo palaciano aspecto de Chancelaria. (VASCONCELLOS, s/d, p. 109.)

A aproximação com essa Europa não lusitana é marcada por um parque francês e esculturas de inspiração greco-romana. A tradição é reafirmada com os salões cujos nomes homenageiam sujeitos ilustres que ajudaram a construir o país como é o caso de Rui Barbosa - ou a delimitar nosso território - referência a Alexandre de Gusmão. Assim, tem-se: a Sala Alexandre de Gusmão, Rui Barbosa, Joaquim Nabuco, Esteves Brandão, Lauro Muller, Guerreiro de Castro, Rio Branco e Cabo Frio. O nacionalismo muito presente nos discursos dos diplomatas aparece nas salas Verde, Amarela e Sala dos Índios. É bom lembrar que, além de serem as cores nacionais, o verde e amarelo são também da dinastia Bragança e Habsburgo.

As composições dos elementos decorativos do Palácio no Rio de Janeiro remetem ao apego pelas artes, sofisticação, bom gosto e tradição que são legitimados como sendo de fruição não somente das classes altas, mas das que detinham além de recursos financeiros, alto capital cultural legitimado. A tapeçaria se resume a peças persas, turcas, francesas e espanholas, os móveis e objetos decorativos como relógios e candelabros foram trazidos de Paris. Sem contar ainda o quadro de D. João VI, pintado por Rodolfo Amoedo a partir de Jean Baptiste Debret e, por fim, o quadro de D. Pedro I, também por Rodolfo Amoedo, a partir de Henrique José da Silva. Na sala intitulada Sala Verde encontra-se mobiliário procedente de Minas Gerais, do século XVIII, mas com quadros da escola austríaca, francesa, flamenga e tapete Tabriz (Pérsia), do século XIX. A sala de espera do Ministro das Relações Exteriores, intitulada Sala Amarela, estão uma cômoda 
papeleira luso-brasileira do final do século XVIII, estatuetas votivas de Tanagra, arte grega do período helenístico (323-30 a.C); quadro do embarque do príncipe regente e retrato de D. João VI; cadeira de transição entre João V e D. José; mesa em estilo D. José, entre outros. Essa composição reúne e evidencia a ideia de valorização da tradição nacional unida ao bom gosto na escolha dos objetos que refletem o conhecimento e incorporação de objetos de arte, mobiliário e tapeçaria legitimados.

É importante chamar a atenção ao culto à tradição, aos antepassados e aos valores compartilhados que são observados também em profissionais do Direito, que ainda hoje são em maior número no Itamaraty, eles procuram "[...] criar um ambiente de reverência e culto dos antepassados ou dos valores compartilhados pelo grupo ou pela instituição que ocupa aquele espaço físico" (ALMEIDA. 2010, p. 51). Na sede carioca, a entrada do Palácio é ladeada com o busto de notáveis: diplomatas e personalidades da política brasileira e mundial ${ }^{13}$. O culto à instituição e ao seu patrono é acompanhada também da memória dos líderes, dos vencedores.

FIGURA 4 - Palácio do Itamaraty, Rio de Janeiro: corredor de entrada

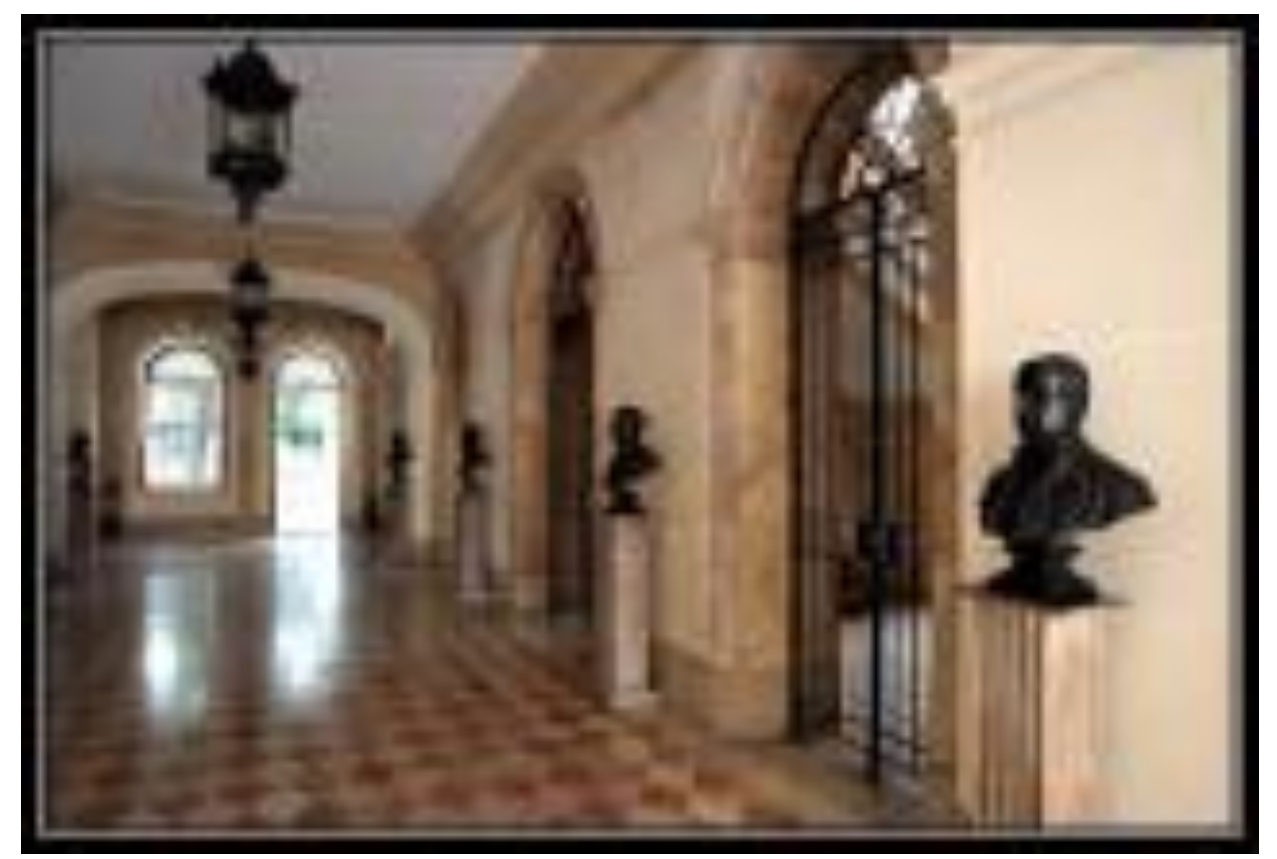

Fonte: www.pbase.com. (2015)

Uma das atribuições dada ao Itamaraty no começo do século $\mathrm{XX}$ era de ser um reduto de monarquistas (ALONSO, 2007; CARVALHO, 2012; FREYRE, 2010).

${ }^{13}$ Dentre os bustos estão o de Rui Barbosa, Alexandre de Gusmão e Joaquim Nabuco. 
No final do século um candidato se referia à instituição como "último reduto da nobreza no Brasil." (MOURA, 2009, p. 53). Embora a arquitetura modernista seja avessa à ideia de monumento, essa noção é preservada quando se trata do espaço da diplomacia brasileira, em que valores ligados à nobreza e aristocracia permanecem presentes. Como fica evidenciado na apresentação do Palácio do Itamaraty, no site da instituição:

O Palácio é uma espécie de cartão de visita do Brasil e traduz, em cada um dos seus detalhes, ideais e valores caros à diplomacia brasileira. Primeiro, a inspiração no passado, no esforço e no talento daqueles que tanto fizeram pelo Brasil. A força do Palácio nos envolve como um legado. Segundo, a vibração do presente, reflexo da dedicação cotidiana de todos nós na busca de um país melhor, de um mundo mais justo e solidário. E, terceiro, a utopia do futuro, para o qual o Palácio parece a todo tempo apontar, na dualidade de sua elegância e simplicidade, nas suas formas arejadas e amplas. Para estar à altura da sede da Chancelaria brasileira e expressar a ousadia pioneira da nova capital, o Palácio precisava traduzir o talento da arquitetura moderna brasileira. Devia ser ao mesmo tempo criativo e funcional, a ponto de conciliar o moderno com o monumental, a simplicidade com a elegância. É nesse ponto que a nudez do concreto armado, um dos traços característicos do Palácio, vai adquirir, nas palavras de Yves Bruand, 'uma nobreza e delicadeza sem igual.[...] Até então, ninguém tinha ousado empregá-lo como elemento sofisticado numa obra de essência aristocrática, como era um palácio que realmente merecesse esse nome; ora, foi esse o tour de force de Niemeyer e sua tentativa se revelou um golpe de mestre'. (MINISTÉRIO DAS RELAÇÕES EXTERIORES, 2009, p. 6)

Legado, elegância e simplicidade, nobreza, sofisticação e a essência aristocrática são os termos usados para descrever o ambiente e que também descrevem seus agentes. A descrição do espaço de estilização da vida diplomática é mesma encontrada nas memórias de seus agentes, tidos como elegantes, de traços nobres, sofisticados, com histórias que muitas vezes remetem ao Império ou o começo da República ${ }^{14}$. Horácio Lafer, ministro de Juscelino Kubitschek (19551960), na inauguração da pedra fundamental do edifício, discursou:

${ }^{14}$ Dentre as biografias estão: Viana, Spektor, Alonso, Santos, Araújo, Corrêa, Gouvêa, Lima, Scarabôtolo, Vieira, Vasconcellos. As memórias e depoimentos são: Luiz Felipe Lampreia, Vasco Leitão da Cunha, Marcos Azambuja, Luís Gurgel Amaral, André Amado, Mario Gibson Barbosa, Celso Amorim, Raul Bopp. Dentre os entrevistados estão: Luiz Felipe Lampreia, Alberto da Costa e Silva Álvaro Franco, Mário Gibson Barbosa, Sérgio Coury, Rubens Ricupero, Fernando Guimarães Reis, Luiz Felipe Seixas Correia e mais cinco diplomatas que se encontram no exercício da função, por isso não serão nomeados no presente trabalho. 
[...] se chamará Palácio do Itamaraty, nome que evoca a tradição que enobreceu e enobrece a diplomacia brasileira [...] o nome Itamaraty está indissoluvelmente ligado aos grandes nomes de nossa diplomacia. Cabe preservar a ambos, isto é, o espírito da tradição e da seriedade que tem caracterizado nossa política exterior e o nome, símbolo daquele espírito durante mais de meio século (MENDES, 1995, p. 30).

A manutenção da tradição materializada nos traços arquitetônicos está também no diálogo entre as duas sedes. As arcadas, referência à arquitetura clássica, não tem caráter estrutural, mas tem a função de carregar a carga simbólica do Palácio, além de novamente relacioná-lo com a antiga sede.

Os arcos da fachada principal assobradada que se abriam em balcões para a cidade, transformaram-se num terraço-jardim, abrindo-se para a Esplanada dos Ministérios. A frontaria alinhada ao logradouro é transformada numa arcada sobre um espelho d'agua que contorna todo o edifício. Também é comum aos dois edifícios a existência de um átrio que valorize a escada, hierarquizando os ambientes que ela conecta: Salão nobre, Salão de bailes, Salão de banquetes e outros salões. Ao invés das palmeiras imperiais, em Brasília há um renque de buritis e plantas aquáticas nos jardins que foram projetados por Burle Marx. Também nos cuidados com os espaços internos se mantém a preocupação de articular móveis antigos e obras de arte, mas incluindo móveis modernos e obras contemporâneas. (ROSSETI, 2009. s/p)

Enquanto as embaixadas da Austrália e Itália já estavam terminadas e começando a funcionar, os diplomatas brasileiros insistiam em permanecer no Rio de Janeiro (Mendes. 1995). Mário Gibson Barbosa, ministro no governo Médici (1969-1974), disse ser a transferência de sede um dos aspectos mais difíceis da sua gestão à frente do Itamaraty: "A mudança do ministério para Brasília e o sequestro dos embaixadores foram dois assuntos que me tomaram muito tempo e que não tinha nada a ver com a política externa." (Entrevista de 15/09/2006).

O Palácio de Brasília foi inaugurado em 1967, sendo mencionado pela Revista Manchete como "o Cisne Branco do Planalto" (ROSSETTI, 2009). Ele é circundado por um espelho d'água com ilhas que abrigam mais de 80 variedades de plantas tropicais presentes no país, principalmente da Amazônia e do Cerrado. Neste projeto paisagístico, conduzido por Burle Marx, a leitura não é apenas enfatizar os aspectos da nossa flora, mas destacá-la como um forte símbolo de 
nacionalidade. A escultura de Bruno Giorgi, Meteoro, fica à frente do Palácio, representando os cinco continentes do planeta. Dentre os elementos que não podem faltar em nenhum Palácio estão presentes no Salão de Honra, de Música e de Baile. Enfim, mesmo com a mudança de sede, o Itamaraty procura cumprir o papel que ele tinha sob os anos Rio Branco. "O Itamaraty era, para Rio Branco, o solar onde a Nação recebia seus mais ilustres hóspedes, acolhendo-os fidalgamente." (VASCONCELLOS. s/d, p. 149)

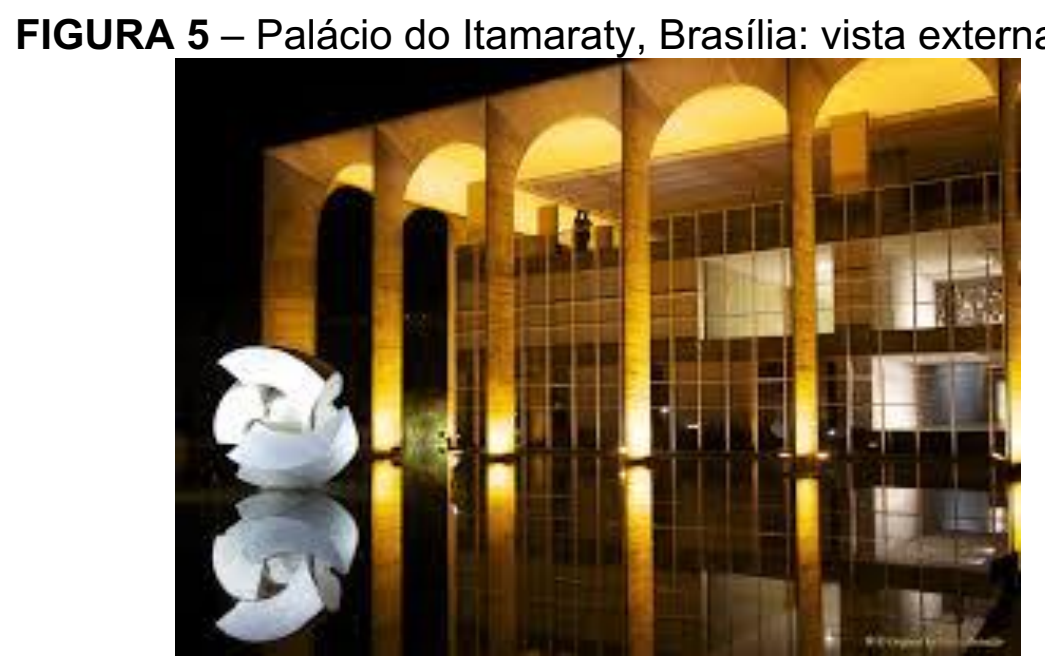

Fonte: www.flickr.com. (2015)

No ambiente interno, as salas e salões são relacionais, podendo ser utilizados de acordo com o evento proposto. Somando todo esse espaço, tem-se 3.300 metros quadrados dedicados à representação diplomática. $\mathrm{O}$ acesso aos grandes salões de festas é dado através de uma escada que parece pairar no ar e que obriga a observação de toda sua extensão:

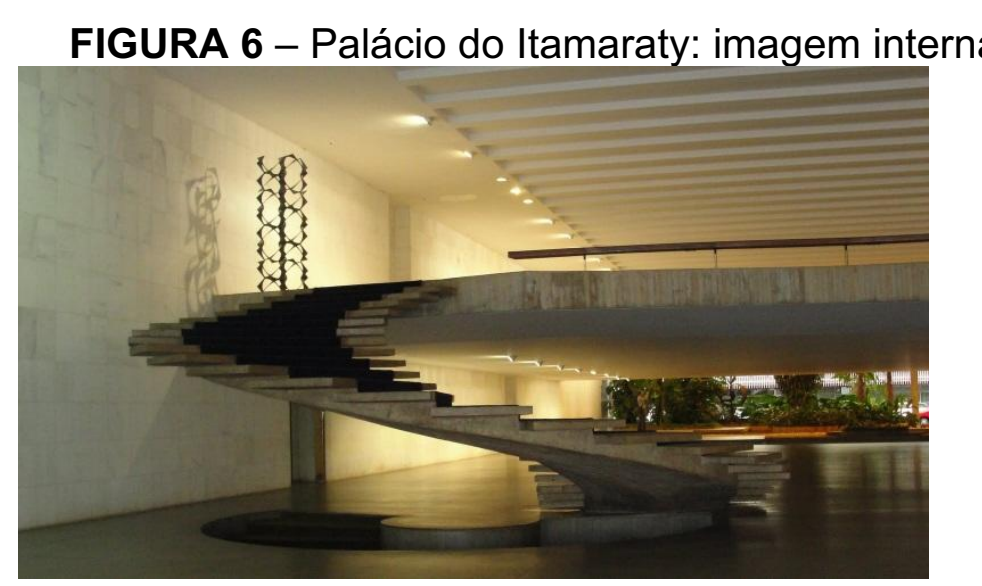

Fonte: www.alynemattos.com. (2015) 
Embora a sede carioca tenha sido endereço da diplomacia brasileira já na República, a ancestralidade imperial brasileira é fortemente preservada, com uma sala dedicada ao Imperador. Nela há a tapeçaria francesa do século XIX, um quadro de D. Pedro II, a partir de Vitor Meirelles e de Rodolfo Amoedo, além de outro da Sessão do Senado onde ocorreu o Juramento da Princesa Isabel assumindo a regência em 25 de maio de 1875. O culto ao Império se mantém na sede de Brasília com as salas D. Pedro I, D. Pedro II. Como foi mencionado anteriormente, alguns autores apresentam o Itamaraty como um espaço de predileção daqueles que cultivavam valores monárquicos. Neste sentido, é interessante pontuar que tanto na sede do Rio de Janeiro, como na de Brasília, temos várias referências à monarquia na nomeação dos espaços, e nenhuma em que se celebre a nossa República.

O alto capital cultural inscrito na história e reproduzido pelos seus agentes está objetivado no acervo de arte brasileira que atrai grande número de visitantes. Este é o único Ministério que tem obras como: O Beijo (Rodin), maquete para Guerra e Paz (Portinari), tapeçaria de Madeleine Colaço. A valorização da história política e dos artistas brasileiros estão por conta do retratos de Duarte da Ponte Ribeiro, Hipólito José da Costa, Pedro II e Deodoro; obras de Di Cavalcanti, de Antonio Bandeira, escultura de Luisa Miller, de Pedro Américo (O grito do Ipiranga e Coroação de Pedro I), de Manabu Mabe, de Tomie Otake, de Aldo Bonadei, escultura de Maira Martins em bronze dourado, de Alfredo Ceschiatti e de Victor Brecheret em gesso polido "inacabado, cujo bronze se encontra no Largo do Arouche, em São Paulo." (Palácio Itamaraty Brasília. 1993, p. 23). Na sala Dom Pedro I, em Brasília, o destaque é o quadro de Debret, Coroação de Pedro I. Como era de se esperar, o que se encontra nestes espaços são elementos que seus agentes reconhecem, valorizam e reproduzem em suas residências particulares.

Parte da mobília foi trazida do Palácio do Rio de Janeiro. Outra parte, além das obras da designer Anna Niemeyer, também são parte da história do Brasil, como a papeleira de Dona Maria I. Foram convidados designers para fazer móveis especialmente para o Itamaraty: Tenreiro, Jorge Hue, Bernardo Figueiredo, Bergmiller e Sérgio Rodrigues. Móveis do século XVIII também se encontram presentes. A mesa dos tratados, onde são assinados os documentos brasileiros, é francesa e data do século XIX. Três salas levam os nomes das três capitais 
brasileiras: Brasília, Bahia e Rio de Janeiro. Numa das salas também abriga um tapete persa de $14 \times 5$, um dos maiores do mundo.

[...] enfatiza-se uma lógica relacional em que tanto as obras de arte como as peças do mobiliário são consideradas mutuamente. Os quadros, as tapeçarias e as esculturas da coleção do Palácio convivem com arcazes, cadeiras, aparadores, canapés, marquesas, papeleiras, além das louças, da prataria e dos tapetes. Menos do que a finesse, vale a função imprescindível que os tapetes persas desempenham na configuração das salas, caracterizando ambiências em meio ao espaço contínuo, demarcando um lugar como o tapete preto de Mies van der Rohe no Pavilhão de Barcelona em 1929, ou como o próprio Niemeyer resolvera o Salão Verde do Congresso Nacional, com tapetes circulares sobrepostos ao carpete. (ROSSETTI, 2009, s/n)

Há também, na entrada da Sala Brasília (grande sala de jantar com capacidade para 180 lugares), um piano Steinway, de "mais de 75 anos (que) vem sendo usado nos concertos organizados no Itamaraty a partir da gestão do Ministro Fernando Henrique Cardoso" (Palácio do Itamaraty Brasília. 1993, p. 20).

A montagem e decoração da nova casa da diplomacia brasileira não foi realizada por um design de interiores, um decorador ou arquiteto, mas por alguém da Casa, o Embaixador Wladimir do Amaral Murtinho. O diplomata acompanhou também as obras do Palácio junto com Oscar Niemeyer e Lucio Costa. Murtinho teria até mesmo resguardado as plantas e projetos quando ocorreu o golpe militar de 1964, para que nada fosse destruído. Niemeyer concordava com Murtinho que o "O Ministério das Relações Exteriores é uma instituição extremamente diferente dos outros ministérios" (ROSSETTI. 2009, s/n). Olavo Redig de Campos, outro membro do Itamaraty, foi responsável pela construção e decoração da edificação. É qualificado pelos colegas como alguém diferenciado pela sua formação em Roma. Murtinho dizia que ele tinha "um conhecimento do que são salões, do que é espaço [...] do que é luxo" (ROSSETTI. 2009, s/n). Esta afirmação deixa evidente o peso do caráter distintivo que consiste no conhecimento de elementos que remetem à sofisticação e elegância de seus agentes e que está intimamente associada ao seu capital cultural formado através da vivência e socialização em grandes centros representantes da arte e cultura ocidentais legítimas, como Roma, Paris ou Londres. Considerando que a decoração, os edifícios e os espaços urbanos estão historicamente vinculados ao exercício de poder de quem os solicita 
(NASCIMENTO. 2017) e às disposições de seus agentes, compreende-se porque diplomatas de carreira são destacados para acompanhar todo o processo. Só eles seriam capazes de conduzir os profissionais para construir algo que correspondesse ao alto capital cultural que esse grupo atribuído a este grupo.

Como é possível notar, ideias consagradas de como ilustração, sofisticação, tradição, arte, aristocracia monárquica são habitus da diplomacia brasileira materializados na arquitetura e organização. Estes elementos os distinguem, diferenciam e distanciam dos agentes exógenos, ao mesmo tempo em que os aproximam de seus pares estrangeiros. Constituem-se, assim, como distintivos da instituição e de seus atores diante do restante do aparelho de Estado e semelhantes aos diplomatas de qualquer nacionalidade. Dentre os órgãos do Estado, eles representam, para os de fora, a capacidade de apreciação e preservação da arte, da memória e das tradições brasileiras ${ }^{15}$, além de aspectos consagrados e naturalizados como a sofisticação e o bom gosto hegemônicos. Por exemplo, os Ministérios da Cultura ou da Educação, que poderiam concorrer com o Itamaraty como guardiões da nacionalidade e da cultura hegemônica, ocupam edificações muito semelhantes às dos demais. Apesar de um orçamento maior, seus espaços não são de cultivo da fruição estética ou da história e memória nacionais.

\section{Considerações Finais}

Como se pretendeu demonstrar no texto acima, no Palácio do Itamaraty temse a materialização de todo um capital simbólico reproduzido pelos agentes do campo diplomático. Esses elementos arquitetônicos ou decorativos não são apenas

\footnotetext{
${ }^{15}$ As informações presentes no site do Ministério das Relações Exteriores ratificam essa noção "Além da arquitetura, e totalmente integrada a ela, merece destaque o importante acervo de obras de arte do Itamaraty, que valoriza o seu interior e combina, de forma harmônica, tradição e inovação. No imenso vão do andar térreo, encontra-se a escultura polivolume de Mary Vieira, "Ponto de Encontro", formada por mais de 200 lâminas móveis de alumínio anodizado. Um pouco além, está a enigmática escultura "A Mulher e sua Sombra", de Maria Martins. Na lateral, pode-se apreciar a parede de mármore em baixo-relevo de Athos Bulcão. Ao fundo, vemos os jardins aquáticos de Burle Marx. Tudo isso dá a exata medida do constante diálogo entre arquitetura e arte, que acompanha o visitante ao longo de todos os espaços do Palácio Itamaraty. Além dos quadros e esculturas, integram o acervo variado mobiliário, tapeçarias e peças artísticas, como os dois anjos de 1737 , que pertenciam à Igreja de São Pedro dos Clérigos, demolida na abertura da Avenida Presidente Vargas, no Rio de Janeiro. Atualmente, os anjos estão suspensos em frente ao espelho negro da Sala Portinari, no terceiro andar" (MINISTÉRIO DAS RELAÇÕES EXTERIORES, 2009, p. 9-10)
} 
fruto do capital cultural incorporado de seus profissionais, mas o são também. No caso analisado, há uma edificação diferente de todo o conjunto ministerial localizado em Brasília, que procura objetificar as disposições corporais e mentais desses agentes.

Primeiro, a construção e decoração deste prédio não pôde ser conduzida apenas por profissionais como arquitetos, decoradores, paisagistas. Ele foi acompanhado, supervisionado por agentes da Casa, a aqueles que são capazes de espelhar de forma fidedigna os elementos históricos e sociais que precisam ser reproduzidos como representativos daquele grupo.

Segundo, todos os aspectos das duas sedes remetem aos ideais aristocráticos da sociedade de corte, analisada por Elias. A forma mais evidente disso está na nomeação de suas salas. Não há uma única referência à República, em todas elas a menção é ao período imperial ou aos cidadãos mais ilustres.

Finalmente, o que se espera neste artigo é exercitar um olhar não arbitrário sobre algumas edificações. Neste caso, por exemplo, para além do caráter histórico e arquitetônico, eles também representam elementos claros sobre a gênese do campo e do habitus diplomáticos, já que suas edificações que são os espaços por excelência de apresentação, espetacularização e exercício da distinção, do poder e da violência simbólica exercida por este grupo.

\section{Referências Bibliográficas:}

ALMEIDA, Frederico Normanha Ribeiro de. (2010), A nobreza togada: as elites jurídicas e a política da justiça no Brasil. Tese do doutorado. Faculdade de Filosofia, Letras e Ciências Humanas - USP. São Paulo, 329 p.

ALONSO, Angela. (2007), Perfis brasileiros: Joaquim Nabuco. São Paulo: Companhia das Letras. $354 \mathrm{p}$.

AMADO, André. (2013), Por dentro do Itamaraty: impressões de um diplomata. Brasília: Funag. $184 \mathrm{p}$.

AMARAL, Luis Gurgel. (1947), O meu velho Itamarati: (de amanuense a secretario de legação) 1905-1913. Rio de Janeiro: Imprensa Nacional. 364 p.

AZAMBUJA, Marcos. (2011), Casa bem-assombrada: O Itamaraty antes da sua ida para Goiás. In: Revista Piauí. Edição 54. 
BALBINO, Viviane Rios. (2011), Diplomata, substantivo comum de dois gêneros: um retrato da presença feminina no Itamaraty no início do século XXI. Brasília: Fundação Alexandre de Gusmão. 212 p.

BARBOZA, Mário Gibson. (2002), Na diplomacia o traço todo da vida. Rio de Janeiro: Francisco Alves Editora. 528 p.

BARROSO, Gustavo. (1968), História do Palácio Itamaraty. Museu Histórico Diplomático do Itamaraty: Rio de Janeiro.

BOPP, Raul. (1968), Memórias de um Embaixador. Rio de Janeiro: Gráfica Record Editora.

BOURDIEU, Pierre. (1979), La distinction: critique sociale du jugement. Paris: Les Éditions de Minuit. $672 \mathrm{p}$.

. (2005). Razões Práticas. Campinas: Papirus. 2005. p. 13 - 33.

(2009). O senso prático. Rio de Janeiro: Vozes

Brasil. Ministério do Planejamento, Desenvolvimento e Gestão. Secretaria de Orçamento Federal. Orçamentos da União exercício financeiro 2018: projeto de lei orçamentária. - $\quad$ Brasília, 2017. Disponível em: file:///C:/Users/User/Downloads/Volume\%20I.pdf

CARVALHO, José Murilo. (2012), Os bestializados. São Paulo: Companhia das Letras. $196 \mathrm{p}$.

CHEIBUB, Zairo Borges. Diplomacia e Construção Institucional: O Itamaraty em Perspectiva Histórica. Dados, Rio de Janeiro, n 28, p. 113-131. 1985.

Diplomacia, Diplomatas e Política externa: Aspectos do processo de institucionalização do Itamaraty. Rio de Janeiro, Dissertação de Mestrado, Instituto Universitário de Pesquisas do Rio de Janeiro. 1984.

CORRÊA, Luiz Felipe de Seixas. (2012), O barão do Rio Branco no centenário de sua morte: memória, inspiração, legado. Cadernos do CHDD. Ano 11. Número especial.

CUNHA, Vasco Leitão. (1994), Diplomacia em Alto mar: depoimento ao CPDOC. Rio de Janeiro: Editora FGV.

ELIAS, Norbert. (2001), A sociedade de corte. Rio de Janeiro: Jorge Zahar Editores. 2001.

FARIA, Carlos Aurélio Pimenta De. Opinião pública e política externa: insulamento, politização e reforma na produção da política exterior do Brasil. Revista Brasileira de Política Internacional, São Paulo, vol 51, n 2, 2008. p. 80-97.

FREYRE, Gilberto. (2010) Ordem e Progresso. Rio de Janeiro: Nova Aguilar Editores. 
GOUVÊA, Fernando da Cruz. (1976), Oliveira Lima: Uma biografia. Recife: Instituto Arqueológico, Histórico e Geográfico Pernambucano.

GUERREIRO, Ramiro Saraiva. (1992), Lembranças de um empregado do Itamaraty. São Paulo: Siciliano. . (1985), Depoimento. Rio de Janeiro: CPDOC. 1985.

LAMPREIA, Luiz Felipe. (2010), O Brasil e os ventos do mundo. Rio de Janeiro: Objetiva.

LEQUESNE, Christian. (2017). Etnographie du Quai d'Orsay. Paris : CNRS Editions.

LIMA, Oliveira. (1937), Memórias: estas minhas reminiscências. Rio de Janeiro: Livraria José Olympio Editora.

LOUREIRO, Maria Rita; ABRUCIO, Fernando Luiz; PACHECO, Regina Silvia (orgs.). Burocracia e política no Brasil: desafios para a ordem democrática no século XXI. Rio de Janeiro: Editora FGV. 2010.

MENDES, Manuel. (1995), O Cerrado de Casaca. Brasília: Editora Thesaurus.

MOURA, Cristina Patriota. (2009), O Instituto Rio Branco e a Diplomacia Brasileira: um estudo de carreira e socialização. Rio de Janeiro: FGV.

MUNDORAMA. Filhos da democracia: A descolonização da diplomacia brasileira. 2015, Disponivel em: http://www.mundorama.net/2015/02/24/filhos-da-democraciaos-diplomatas-brasileiros-na-nova-republica-1985-2010-por-rogerio-de-souza-fariase-gessica-carmol.

ORTIZ, Renato. (2006), A moderna tradição brasileira: Cultura Brasileira e Indústria Cultural. São Paulo: Brasiliense.

PALÁCIO ITARAMATY BRASÍLIA: Brasília, Rio de Janeiro. São Paulo: Banco Safra. 1993.

PEREIRA, João Francisco. (2008), Ramiro, empregado do Brasil. Revista Juca, ano 2.

ROSSETTI, Eduardo Pierrotti. (2009), Palácio do Itamaraty: questões de história, projeto e documentação (1959-70). Revista Arquitextos. Ano 09, mar.

SANTOS, Luís Cláudio Villafañe G. (2012), O Evangelho do Barão. São Paulo: UNESP.

SCARABÔTOLO, Hélio A. (1990), O Barão do Penedo: Diplomata do Império.

SCHUWARCZ, Lilia Moritz. As barbas do Imperador: D. Pedro II, um monarca nos trópicos. São Paulo: Companhia das Letras. 2012. 
TOMASS, Lea Maria. Diferença e igualdade entre os Estados: Uma etnografia da precedência nas relações diplomáticas. Dissertação de Mestrado, Universidade de Brasília. Brasília. 2001.

VASCONCELLOS, Mario de Barros e. (s/d) O Barão do Rio Branco. Biografia. Rio de Janeiro: Ministério das Relações Exteriores.

VIANA FILHO, Luís. (2008) A vida do Barão do Rio Branco. 8. Ed. - São Paulo: Editora UNESPE; Salvador, BA: EDUFBA.

VIEIRA, Marcos Vinicios de Araújo. (2011) José Guilherme Merquior: um diplomata de 900 anos. Revista Juca, ano 5.

\section{Entrevistas:}

ALMEIDA, Paulo Roberto. Paulo Roberto de Almeida: entrevista [ago. 2006]. Entrevistadora: K. Gobo. Curitiba, 2006. 1 cassete sonoro. Entrevista concedida para a dissertação de mestrado "Década de 1970: A política externa e o papel do Itamaraty."

BARBOZA, Mário Gibson. Mário Gibson Barboza: entrevista [set. 2006]. Entrevistadora: K. Gobo. Rio de Janeiro, 2006. 1 cassete sonoro. Entrevista concedida para a dissertação de mestrado "Década de 1970: A política externa e o papel do Itamaraty."

COSTA E SILVA, Alberto da. Alberto da Costa e Silva: entrevista [set. 2006]. Entrevistadora: K. Gobo. Rio de Janeiro, 2006. 1 cassete sonoro. Entrevista concedida para a dissertação de mestrado "Década de 1970: A política externa e o papel do Itamaraty."

COURY, Sérgio. Sérgio Coury: entrevista [set. 2006]. Entrevistadora: K. Gobo. Curitiba, 2006. 1 cassete sonoro. Entrevista concedida para a dissertação de mestrado "Década de 1970: A política externa e o papel do Itamaraty."

FRANCO, Álvaro. Álvaro Franco: entrevista [set. 2006]. Entrevistadora: K. Gobo. Rio de Janeiro, 2006. 1 cassete sonoro. Entrevista concedida para a dissertação de mestrado "Década de 1970: A política externa e o papel do Itamaraty."

GUERREIRO, Ramiro Saraiva. Ramiro Saraiva Guerreiro: entrevista [set. 2006]. Entrevistadora: K. Gobo. Rio de Janeiro, 2006. 1 cassete sonoro. Entrevista concedida para a dissertação de mestrado "Década de 1970: A política externa e o papel do Itamaraty."

LAMPREIA, Luiz Felipe. Luiz Felipe Lampreia [mai. 2007]. Entrevistadora: K. Gobo. Rio de Janeiro, 2006. 1 cassete sonoro. Entrevista concedida para a dissertação de mestrado "Década de 1970: A política externa e o papel do Itamaraty." 